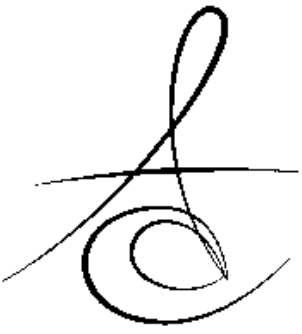

\title{
ÇÜRÜK DİRENCİNİN ARTTIRILMASINDA LAZER VE KAZEİN FOSFOPEPTİD AMORF KALSİYUM FOSFAT'IN BİRLİKTE KULLANIMIN ETKİSİNİN DEĞERLENDİRÍLMESI ${ }^{*}$
}

\author{
EVALUATION OF COMBINED EFFECT OF LASER AND CASEIN \\ PHOSPHOPEPTIDE-AMORPHOUS CALCIUM PHOSPHATE APPLICATION ON \\ INCREASING OF CARIES RESISTANCE ${ }^{\neq}$
}

\author{
Prof. Dr. Şule BAYRAK*
}

Dr. Dt. Elif İpek YILMAZ ${ }^{* *}$

Makale Kodu/Article code: 3094

Makale Gönderilme tarihi: 01.11 .2016

Kabul Tarihi: 18.01.2017

\section{öz}

Amaç: Bu çalışmanın amacı, erbiyumla takviyelenmiş yitriyum alüminyum garnet lazerin kazein fosfopeptid amorf kalsiyum fosfat ile birlikte kullanımının daimi dişlerin çürük oluşumuna karşı direncinin arttırılmasındaki etkilerinin değerlendirilmesidir.

Gereç ve Yöntem: 30 adet daimi diş kullanılarak elde edilen mine örnekleri rastgele 5 gruba ayrıldı; negatif kontrol, asitlenmiş fosfat florit (pozitif kontrol), kazein fosfopeptid amorf kalsiyum fosfat, lazer, lazer+kazein fosfopeptid phosphopeptide amorf kalsiyum fosfat. Gruplara göre yüzey tedavileri uygulandıktan sonra örnekler pH siklusuna tabi tutuldu. Polarize ışık mikroskopisi ile çürük lezyon derinliği, tarayıcı elektron mikroskopisi ile yüzeyde oluşan yapısal değişiklikler değerlendirildi. Elde edilen verilerin istatistiksel değerlendirilmesinde tek yönlü varyans analizi ve Tukey Çoklu Karşılaştırma testi kullanıldı.

Bulgular: Tüm gruplar arasında en yüksek ortalama çürük lezyon derinliği negatif kontrol grubunda $(51,12 \pm 10,79)$, en düşük ortalama çürük lezyon derinliği ise asitlenmiş fosfat florit (pozitif kontrol) grubunda $(24,12 \pm 11,73)$ gözlendi. Lazerin tek başına ve CPP-ACP ile birlikte uygulanması karşılaştırıldığında, gruplar arasında istatistiksel olarak anlamlı bir farklılık saptanmadı $(p>0,05)$. Taramalı elektron mikroskobu incelemesinde ise tüm gruplarda uygulanan yüzey hazırlama işlemlerine göre morfolojik değiş̧imlerin olduğu gözlendi.

Sonuç: İn vitro olarak yapılan bu çalışma sonucunda, daimi dişlerin çürük direncinde erbiyumla takviyelenmiş yitriyum alüminyum garnet lazerin, kazein fosfopeptid amorf kalsiyum fosfat ile birlikte kullanımın tek başına kullanıma göre ilave bir katkı sağlamadığı belirlendi.

Anahtar Kelimeler: Diş çürüğüne direnç, diş minesi, kazein fosfopeptid amorf kalsiyum fosfat, lazer

\section{ABSTRACT}

Aim: The aim of this study was to evaluate the effects of erbium-doped yttrium aluminum garnet laser combined with casein phosphopeptide-amorphous calcium phosphate treatments on caries resistance of permanent teeth.

Material and Methods: The enamel samples were obtained from 30 permanent teeth and randomly divided into five groups; negative control, acidulated phosphate fluoride (positive control), casein phosphorpeptideamorphous calcium phosphate, laser, laser+ casein phosphopeptide-amorphous calcium phosphate. The surface treatments were applied; the samples were then submitted to $\mathrm{pH}$ cycle. Lesion depth was measured by polarized light microscopy, and the morphological changes on the sample surfaces were analyzed by scanning electron microscopy. The statistical analyses of obtained data were performed using one-way analysis of variance and Tukey Multiple Comparison test.

Results: Mean lesion depth was greatest in the negative control group $(51.12 \pm 10.79)$, and lowest in the acidulated phosphate fluoride group fluoride (positive control) (24.12 \pm 11.73 ). When compared the laser group and laser combined with casein phosphopeptideamorphous calcium phosphate, no statistically significant differences in mean lesion depth values were found between groups $(p>0.05)$. Scanning electron microscopy examination also revealed obvious morphological changes in all groups.

Conclusion: As a result of this in-vitro study determined that the combined application of aluminum erbiumdoped yttrium garnet laser with casein phosphorpeptideamorphous calcium phosphate no showed an added beneficial effect compared with erbium-doped yttrium aluminum garnet laser alone on caries resistance of permanent teeth.

Keywords: Dental caries resistance, dental enamel, casein phosphopeptide-amorphous calcium phosphate, laser.

\footnotetext{
*Eskişehir Osmangazi Üniversitesi, Diş Hekimliği Fakültesi, Çocuk Diş Hekimliği Anabilim Dalı, Eskişehir,

${ }^{* *}$ Serbest Çocuk Diş Hekimi, Bursa, Türkiye

${ }^{7}$ Bu çalışma, Belgrad-Sırbistan'da 2-5 Haziran 2016 tarihinde "13 $3^{\text {th }}$ European Academy of Paediatric

Dentistry" kongresinde tebliğ edilmiştir ve Bu çalışma, Ondokuz Mayıs Üniversitesi Bilimsel

Araştırma Projeleri Başkanlığı'nca PYO.DIS. 1904.11.010 numarasıyla desteklenmiştir.
} 


\section{GİRIŞ̧}

Geri dönüşümsüz, çok faktörlü, enfeksiyöz ve transfer olabilen bir hastalık olarak kabul edilen diş çürüğü, ${ }^{1}$ çocukluk döneminde yaygın olarak görülen kronik hastalıklardan biridir. ${ }^{2}$ Diş çürüğü, gelişmiş ülkelerde koruyucu hekimlik alanında yapılan ilerlemelerle belirgin oranda azalmasına rağmen, gelişmekte olan ülkelerde hala önemli bir problemdir. ${ }^{2-4}$

Çürük olayının erken safhalarında, bakterilerin karbonhidratları fermente etmesi sonucu ağız ortamının pH'sı kritik pH'nın $(<5,5)$ altına düşmekte ve mine minerallerinin çözünmesi ile sonuçlanmaktadır., ${ }^{3,5} \mathrm{Bu}$ nedenle diş çürüğünün önlenmesinde, mine yüzeyinin remineralizasyon mekanizmasını arttırmaya teşvik ederek aside karşı dişlerin direncini geliştirmek önemlidir. ${ }^{5}$ Diş dokularının çürük oluşumuna karşı direncini arttırmak amacıyla en yaygın olarak kullanılan ajan florit (F)'tir. ${ }^{6}$ Topikal olarak uygulanan $F$ etkisini, mineral yapının çözünürlüğünü azaltarak, remineralizasyonu arttırarak ve plak bakterileri tarafından asit üretimini engelleyerek göstermektedir. ${ }^{6-9}$ Ancak topikal olarak uygulanan F'lerin diş çürüğü oluşumunu önlemede tek başına yetersiz kalması ${ }^{10}$ ve yaygın olarak kullanılmasının florozise neden olması gibi dezavantajlara sahip olması ${ }^{11}$ diş dokularının çürük oluşumuna karşı direncini arttıran yeni ajan ve yöntemlerin aranmasına yol açmıştır.

Günümüzde F'lere alternatif olarak gösterilen kazein fosfopeptid amorf kalsiyum fosfat (CPP-ACP), ağız ortamında yüksek çözünürlüğüne sahip olması ve hızlı bir şekilde apatit formuna hidrolize olması nedeniyle çürük oluşumunu önlemede etkili bir ajan olarak kabul edilmektedir. ${ }^{12,13}$ Diş hekimliğinin birçok alanında yaygın olarak kullanılan lazerinde, ${ }^{14-18}$ mine yüzeyinde morfolojik ve kimyasal değişikler oluşturarak diş dokularının çürük oluşumuna karşı direncinin arttırılmasında da etkili olduğu ileri sürülmektedir. ${ }^{14,19-29}$

Daimi dişlerin çürük oluşumuna karşı direncinin arttırılmasında lazer ile ilgili çalışmalar incelendiğinde, lazerin tek başına ${ }^{14,19,24-26,28,29}$ ya da F ile birlikte kullanılmasının 22,30-33 etkinliğini değerlendiren çalışmalar olmasına rağmen, lazer ile CPP-ACP'nin birlikte uygulanmasının etkinliği hakkında yeterli bilgi mevcut değildir. Bu nedenle çalışmamızda, erbiyumla takviyelenmiş yitriyum alüminyum garnet (Er:YAG) lazerin CPP-ACP ile birlikte kullanımının daimi dişlerin çürük oluşumuna karşı direncinin arttırılmasındaki etkilerinin karşılaştırmalı olarak değerlendirilmesi amaçlandı.

\section{GEREÇ ve YÖNTEM}

Çalışmanın yürütülebilmesi için gerekli olan etik izin Ondokuz Mayıs Üniversitesi Tıbbi Araştırma ve Etik Komisyonu'ndan (Karar No: 20119/286) alındı. Helsinki Deklarasyonu Prensipleri'ne uygun olarak yapılan çalışmada, çekim endikasyonu bulunan dişlerin çalışmamızda kullanılabilmesi için, hasta ve ebeveynlerine araştırma ile ilgili detaylı bilgi verildikten sonra, hasta ve/ veya ebeveynlerinden imzalı bilgilendirilmiş olur formları alındı.

\section{Calışmada Kullanılan Materyaller}

Çalışmamızda, \%5-10'luk CPP-ACP patı ve pH'sı 3 olan \%1,23'lük asitlenmiş fosfat florit (APF) jeli kullanıldı (Tablo 1).

Tablo 1. Araştırmada kullanılan materyaller

\begin{tabular}{|c|c|c|}
\hline Ürün Adı & İçeriği & Üretici Firma \\
\hline $\begin{array}{l}\text { GC Tooth } \\
\text { Mousse }\end{array}$ & $\begin{array}{l}\text { \%5-10 kazein fosfopeptid amorf kalsiyum } \\
\text { fosfat, saf su, gliserol, sorbitol, silikon } \\
\text { dioksit, sodyum karboksimetilselüloz, } \\
\text { propilen glikol, titanyum dioksit, ksilitol, } \\
\text { fosforik asit, çinko oksit, sodyum sakkarin, } \\
\text { etil p-hidroksibenzoat, magnezyum oksit, } \\
\text { propil p-hidroksibenzoat, bütil p- } \\
\text { hidroksibenzoat, tatlandırıcı }\end{array}$ & $\begin{array}{l}\text { GC } \\
\text { Corporation } \\
\text { Tokyo, Japan }\end{array}$ \\
\hline $\begin{array}{l}\text { Topex APF } \\
\text { Jel }\end{array}$ & $\begin{array}{l}\text { Hidroflorik asit, fosforik asit, saf su, sodyum } \\
\text { benzoat, sodyum florit, tatlandırıcl, sodyum } \\
\text { sakkarin, ksilitol }\end{array}$ & $\begin{array}{l}\text { Sultan Dental } \\
\text { Products, New } \\
\text { Jersey, USA }\end{array}$ \\
\hline
\end{tabular}

Araştırmamızda kullanılan CPP-ACP patı bir aplikatör yardımı ile 3 dakika, APF jeli ise 4 dakika süre ile uygulandı. Uygulama sonrası örnekler distile su ile yıkandı.

\section{Çalışmada Kullanılan Lazer Cihazı}

Araştırmamızda, dalga boyu 2,94 mikrometre $(\mu \mathrm{m})$ olan Er:YAG lazer (Fidelis III AT, Fotona, Ljubljana, Slovenia) kullanıldı.

Mine yüzey hazırlama işlemlerinde, üretici firmanın önerileri doğrultusunda, cihazın gücü 0,4 Watt (W), frekansı 2 Hertz $(\mathrm{Hz})$, atım enerjisi 200 milijoule $(\mathrm{mj})$, atım aralığı 300 mikrosaniye ( $\mu \mathrm{s})$ olarak ayarlandı. Lazer enerjisinin mine yüzeyine iletilmesinde cihazın kendisine ait olan R02-C non-kontakt uç kullanıldı. Cihazın ucu deney örneklerinden, yaklaşık 12 milimetre (mm) uzakta tutulup, susuz olarak 10 saniye boyunca mine yüzeyine uygulandı.

Mine Örneklerinin Hazırlanması

Işık mikroskobu (Nikon Eclipse E 600, Nikon Corp., Tokyo, Japan) altında değerlendirildikten sonra, çürük, hipokalsifikasyon ve kırık/çatlak bulunmayan 30 adet daimi üçüncü azı dişi çalışmaya dahil edildi. Tüm dişler, üzerinde bulunan yumuşak doku artıkları ve

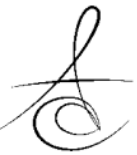


debrisleri kretuar yardımıyla uzaklaştııılıktan sonra florit içermeyen proflaksi patı (Topex Prophy Paste, Sultan Dental Products, New Jersey, USA) ile mikromotor ve firça kullanılarak temizlendi. Dişler deney periyoduna kadar \% 0,1 timol içeren distile su içerisinde ve oda sıcaklığında saklandı.

Çalışmaya dahil edilen dişlerin kökleri, su soğutması altında elmas separe yardımıla, mine-sement sınırından kesilerek uzaklaştııılı. Dişlerin pulpası ekskavatör ile temizlendikten sonra pulpa odaları pembe mum ile kapatıldı. Dişlerin 25 tanesi polarize ışık mikroskopisi (PLM) incelemesi için, kalan 5 tanesi de tarayıcı elektron mikroskopisi (SEM) incelemesi için kullanıldı.

PLM değerlendirilmesinde kullanılacak dişlerin bukkal ve lingual yüzeylerinde $1 \times 3 \mathrm{~mm}$ boyutunda (Şekil 1), SEM değerlendirilmesinde kullanılacak dişlerin ise $2 \times 2 \mathrm{~mm}$ boyutunda (Şekil 1) diş yüzeyi açıkta kalacak şekilde diğer tüm yüzeyleri aside dayanıkı vernikle (239, Flormar, Kocaeli, Türkiye) kaplandı.

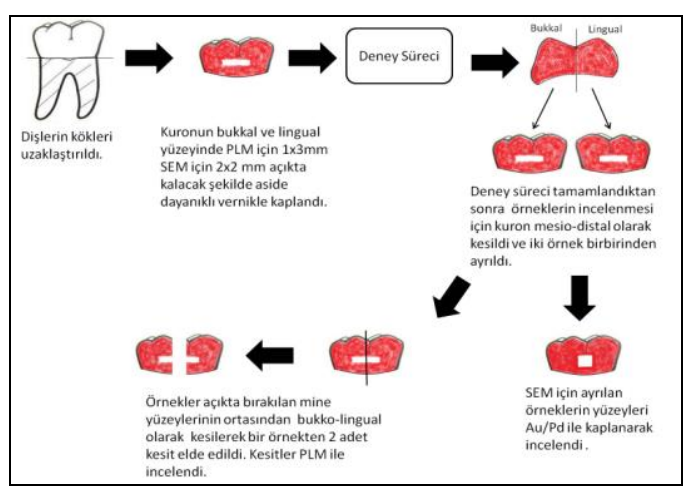

Şekil 1. Mine örneklerinin hazırlanmasının şematik görünümü

Her dişten bukkal ve lingual olmak üzere 2 örnek elde edildi. Buna göre PLM değerlendirilmesinde toplam 50 adet mine örneği, SEM değerlendirilmesinde ise 10 adet mine örneği elde edildi (Şekil 1 ).

Ardından tüm mine örnekleri PLM incelemesi için her grupta 10 adet, SEM değerlendirmesi için ise her grupta 2 adet örnek olacak şekilde rastgele 5 gruba ayrildl;

1. Negatif Kontrol Grubu: Herhangi bir mine yüzey hazırlama işlemi (APF jel, CPP-ACP patı ya da Er:YAG lazer) uygulanmadı.

2. APF Grubu (Pozitif Kontrol Grubu): Sadece APF jel uygulandı.

3. CPP-ACP Grubu: Sadece CPP-ACP patı uygulandı.
4. Er:YAG Grubu: Sadece Er:YAG lazer uygulandı.

5. Er:YAG+CPP-ACP Grubu: Er:YAG lazerden sonra CPP-ACP patı uygulandı.

Gruplarda APF jel ve Er:YAG lazer pH siklusundan önce bir kez uygulanırken, CPP-ACP patı pH siklusu boyunca her demineralizasyon işleminden önce uygulandı.

\section{Mine Örneklerine pH Siklusu Uygulanması}

Tüm gruplardaki örneklere ağız ortamındaki gün boyu değişen $\mathrm{pH}$ değişikliklerini taklit etmek amacıyla ten Cate ve Duijsters' ${ }^{34}$ pH siklus modeli (6 saat demineralizasyon,18 saat remineralizasyon) 10 gün boyunca uygulandı.

Araştırmamızda kullanılan demineralizasyon solüsyonu 1 litre distile su içine; 2,2 milimol (mM) Kalsiyum klorür $\left(\mathrm{CaCl}_{2}\right), 2,2 \mathrm{mM}$ Monosodyum fosfat $\left(\mathrm{NaH}_{2} \mathrm{PO}_{4}\right), 0,05 \mathrm{M}$ asetik asit, $1 \mathrm{M}$ Potasyum hidroksit eklenerek $\mathrm{pH}=4,4$ olacak şekilde hazırlandı. Remineralizasyon solüsyonu ise 1 litre distile su içine; $1,5 \mathrm{mM}$ $\mathrm{CaCl}_{2}, 0,9 \mathrm{mM} \mathrm{NaH} \mathrm{PO}_{4}, 0,15 \mathrm{M}$ Potasyum klorür eklenerek $\mathrm{pH}=7,0$ olacak şekilde hazırlandı.

Lezyon Derinliği Ölçümü

Her örnekten düşük hızda çalışan 0,48 mm elmas bir kesici kullanılarak (Minitom, Struers, Ballerup, Denmark) lezyonun tam ortasından bukko-lingual yönde kesilerek ikişer kesit alındı. Alınan kesitlerin yüzeyi polisaj cihazında (Labopol-5, Struers, Ballerup, Denmark) 400, 800, 1000, 1200, 2000 ve 4000 gritlik su zımparalarıly (Supraflex Paper, English Abrasives\& Chemicals Limited, Stafford, United Kingdom) zımparalandıktan sonra $3 \mu \mathrm{m}$ elmas süspansiyon (Aka-mono, Microtest, İstanbul, Türkiye) kullanılarak parlatıldı.

Kesitler PLM (DM LM, Leica Microsystems, Wetzlar, Germany) altında x20 büyütmede incelendi ve elde edilen görüntüler kaydedildi. Kesit görüntüleri Image Pro-Plus 6.0 programına (Media Cybernetics, Rockville, MD, USA) aktarılarak, lezyon derinliği ölçümleri yapıldı. Her bir kesitteki lezyonun farklı üç bölgesinden $\mu \mathrm{m}$ cinsinden ölçüm yapılarak ortalaması alındı ve ortalama değer o kesitin lezyon derinliği olarak kaydedildi (Şekil 2). Her örnekten iki adet kesit elde edilip lezyon derinliği değerlendirildiği için, istatistiksel analizde her bir grup için örnek sayısı 20 olarak kabul edildi.

Mine Yüzeyinde Oluşan Yapısal Değişikliklerin Değerlendirilmesi

SEM (Leo 440, Zeiss, Cambridge, UK) için hazırlanan mine örnekleri havasız bir ortamda Polaron

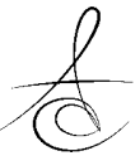


Sc7620 Mini Sputter Coater (Quorum Technologies Ltd, Kent, UK) kullanılarak 30 sn boyunca 90 Angstrom kalınlığında altın/paladyum ile kaplandı. Yüzey kaplaması yapılan örnekler x3000 büyütme SEM altında incelendi.

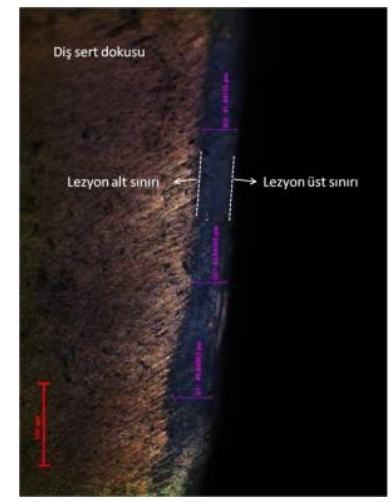

Şekil 2. Lezyon derinliğinin ölçümü

\section{İstatistiksel Değerlendirme}

Elde edilen verilerin istatistiksel analizleri "Statistical Package for the Social Sciences" yazılımı (SPSS 12 for Windows, SPSS Inc., Chicago, Illinois, USA) kulanılarak gerçekleştirildi.

Çalışmamızda elde edilen verilerin istatistiksel olarak değerlendirilmesinde tek yönlü varyans analizi kullanıldı. Eğer farklılık mevcut ise, hangi gruplar arasında farklılık olduğunu tespit etmek için ise Tukey Çoklu Karşılaştırma testi uygulandı.

Analizlerde istatistiksel anlamlılık düzeyi $p<0,05$ olarak kabul edildi.

\section{BULGULAR}

\section{Lezyon Derinliklerine İlişkin Bulgular}

Gruplara ait çürük lezyon derinliklerinin ortalama ve standart sapma değerleri Tablo 2'de, kesitlerin PLM görüntüleri ise Şekil 3'de gösterilmektedir.

Tablo 2. Grupların çürük lezyon derinliklerinin ortalama ve standart sapma değerleri.

\begin{tabular}{l|c|c|}
\hline Gruplar & $\mathbf{n}$ & Mean \pm Standard Deviation(nm) \\
\hline Negatif Kontrol & 20 & $51,12 \pm 10,79^{\mathrm{a}}$ \\
\hline APF (Pozitif Kontrol) & 20 & $24,12 \pm 11,73^{\mathrm{d}}$ \\
\hline CPP-ACP & 20 & $36,33 \pm 10,61^{\mathrm{bc}}$ \\
\hline Er:YAG & 20 & $37,49 \pm 11,50^{\mathrm{bc}}$ \\
\hline Er:YAG+CPP-ACP & 20 & $45,17 \pm 9,84^{\mathrm{ab}}$ \\
\hline & *Farklı harfler gruplar arasındaki istatistiksel farklılıkları \\
göstermektedir (p<0,05).
\end{tabular}
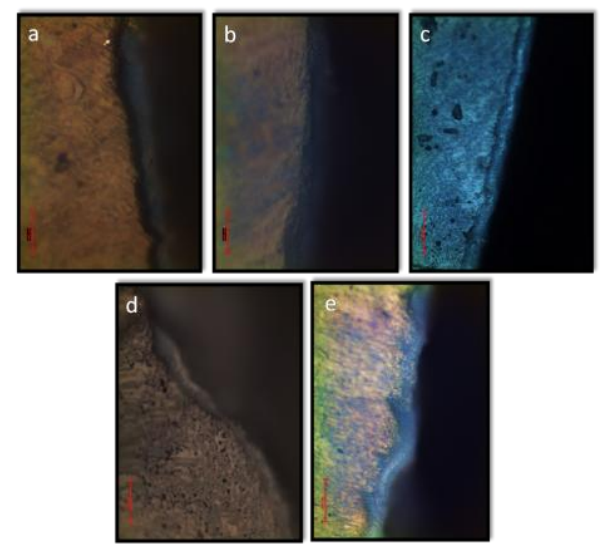

Şekil 3. Gruplara ait PLM görüntüleri (x20): a) Negatif Kontrol Grubu; b) APF Grubu (Pozitif Kontrol); c) CPP-ACP Grubu; d) Er:YAG Grubu; e) Er:YAG+CPP-ACP Grubu

Tüm gruplar arasında en yüksek ortalama çürük lezyon derinliği negatif kontrol grubunda $(51,12 \pm$ $10,79)$, en düşük ortalama çürük lezyon derinliği ise APF(pozitif kontrol) grubunda $(24,12 \pm 11,73)$ gözlendi.

Negatif kontrol grubunun ortalama çürük lezyon derinliğinin, Er:YAG+CPP-ACP grubu hariç, diğer tüm gruplardan anlamlı olarak daha yüksek olduğu belirlendi $(p<0,05)$.

Mine yüzey hazırlama işlemlerinden APF (pozitif kontrol), CPP-ACP ve Er:YAG lazer uygulamaları karşılaştırıldığında, CPP-ACP ve Er:YAG grupları arasında istatistiksel olarak anlamlı bir fark gözlenmezken ( $p>0,05)$, APF (pozitif kontrol) grubunun her iki gruptan da istatistiksel olarak daha düşük ortalama çürük lezyon derinlik değerine sahip olduğu gözlendi $(p<0,05)$.

Lazerin tek başına ve CPP-ACP ile birlikte uygulanmasının ortalama çürük lezyon derinliği karşılaştırıldığında, iki grup arasındaki farkın istatistiksel olarak anlamlı olmadığı tespit edildi ( $p>0,05)$.

Mine Yüzeyinde Oluşan Yapısal Değişikliklerin Bulguları

Negatif kontrol grubunda, bazı bölgelerde prizma periferlerinin ortadan kalktığı ve bu bölgelerin birbirleri ile birleşmesi sonucunda yarıkların ve çukurcukların oluştuğu, bazı bölgelerde ise mine prizmaların açığa çıkmadığı yüzeysel madde kayıpların oluştuğu izlendi (Şekil 4a).

APF (pozitif kontrol) grubunda, mine yüzeylerinde demineralizasyon alanlarının içerisinde ve lezyon yüzeyinde yeni forme olan küçük yuvarlak globüler (kalsiyum florid $\left(\mathrm{CaF}_{2}\right)$ kristalleri) birikimler izlendi (Şekil 4b). 
CPP-ACP grubunda, mine yüzeyinin CPP-ACP patının reaksiyon ürünlerinin oluşturduğu homojen remineralizasyon tabakası ile örtüldüğü saptandı. Oluşan yüzey örtüsü sayesinde poröz yapının kaybolduğu gözlendi (Şekil 4c).

Er:YAG grubunda, lazer uygulaması sonucu mine dokusunun hafif düzeyde çözündüğü, çatlakların ve krater benzeri yapıların oluştuğu ve tespit edildi (Şekil 4d).

Er:YAG+CPP-ACP grubunda, mine prizmalarının lazer uygulaması sonucu hafif derecede erimesi ile oluşan girintili çıkıntılı ve kraterli bir yüzey tespit edildi. $\mathrm{Bu}$ kraterli demineralize yüzeye rağmen mine korlarının tamamen erimediği ve çukurcuklar oluşmadığı gözlendi. Aynı zamanda yoğun çökelmeler şeklinde globüler opak yapılar halinde remineralize alanlar izlendi (Şekil 4e).

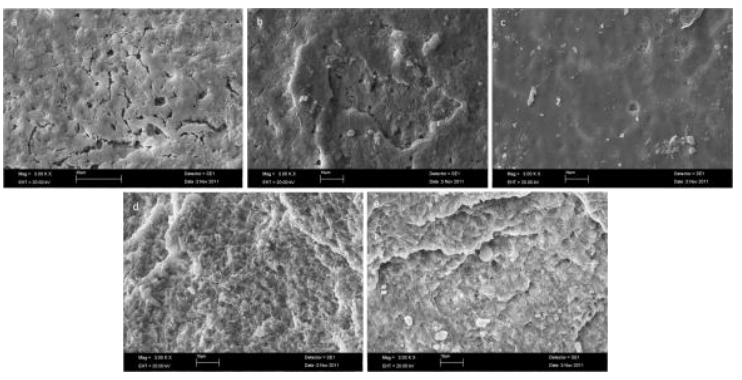

Şekil 4. Gruplara ait SEM görüntüleri (x3000): a) Negatif Kontrol Grubu; b) APF Grubu (Pozitif Kontrol); c) CPP-ACP Grubu; d) Er:YAG Grubu; e) Er:YAG+CPP-ACP Grubu

\section{TARTIŞMA}

Diş çürüğü oluşumunun önlenmesinde; diş dokularının çürük oluşumuna karşı direncinin arttırılması, diş plağının kimyasal ve mekanik olarak kontrol altına alınması, pit ve fissür örtücü uygulanması, beslenmenin düzenlenmesi, ağız ve diş sağlığı konusunda eğitim verilmesi gibi yöntemler uygulanmaktadır. ${ }^{35}$ Son yıllarda, CPP-ACP ve lazer uygulamaları minenin asit ataklarına karşı direncini artırmada popüler hale gelmiştir. ${ }^{14,19,25,26,28,29,36}$ Bununla beraber, minenin asit direncinin arttırılmasında lazer ile CPP-ACP'nin birlikte uygulanmasının etkinliği hakkında yeterli bilgi mevcut değildir. Bu nedenle çalışmamızda, Er:YAG lazerin CPPACP ile birlikte kullanımının daimi dişlerin çürük oluşumuna karşı direncinin arttırılmasındaki etkilerinin karşılaştırmalı olarak değerlendirilmesi amaçlandı.

Günümüzde diş çürüğü oluşumunun önlenme- sinde topikal $\mathrm{F}$ uygulamalarının sistemik uygulamalara göre daha etkili olduğu kabul edilmektedir. ${ }^{9}$ Profesyonel uygulamalarda yaygın olarak kullanılan topikal $\mathrm{F}$ jelleri, \%1,23'lük APF ve \% 2'lik nötral sodyum florit formlarında bulunmaktadır. ${ }^{37}$ Yapılan çalışmalarda, düşük pH'ya sahip olan topikal APF preparatlarının minede daha fazla $F$ tutulumuna neden olduğu ve minenin asit ataklarına karşı direncini daha fazla arttırdığı rapor edilmektedir. ${ }^{38,39}$ Bu nedenle çalışmamızda, mine yüzey hazırlama işlemleri sırasında APF jeli kullandık. Amerikan Diş Hekimliği Birliği profesyonel topikal F jellerin 4 dakika uygulanmasını gerektiğini, daha az sürede uygulandığında yeterli etkiyi göstermediğini bildirmektedir. ${ }^{40} \mathrm{Bu}$ bilgiler ışığında, çalışmamızda APF jeli örneklere 4 dakika süre ile tek sefer uygulandı.

CPP-ACP patı, düşük konsantrasyon $F$ ürünleri gibi günlük uygulan koruyucu bir ajandır. ${ }^{41}$ Yapılan in vitro çalışmalarda CPP-ACP patının 90 sn-3 dakika arasında değişen farklı sürelerde uygulandığı gözlenmektedir. ${ }^{42-46}$ Üretici firma (GC Corporation, Tokyo, Japan) ise CPP-ACP'nin en az 3 dakika uygulanması gerektiğini önermektedir. Çalışmamızda üretici firmanın önerileri doğrultusunda, CPP-ACP patı örneklere her gün 3 dakika süre ile uygulandı.

Diş sert dokularının çürük oluşumuna karşı direncini arttırmada, $\mathrm{CO}_{2},{ }^{23,30,31} \mathrm{Nd}: \mathrm{YAG}{ }^{27} \mathrm{Er}: \mathrm{YAG}_{1}{ }^{19,24-}$ 26,28,29,47 Er,Cr:YSGG, ${ }^{25,33}$ Diyot $^{48}$ gibi birçok farklı dalga boyundaki lazer cihazı kullanılmıştır. $\mathrm{CO}_{2}$ lazerler diş sert dokularının inorganik bileşeni olan HAP kristalleri tarafından fazla miktarda absorbe edildiğinden, ${ }^{49}$ ciddi termal hasar ve karbonizasyona neden olmaktadır. ${ }^{50}$ Nd:YAG ve Diyot lazerler ise diş sert dokuları tarafından çok az absorbe edildiğinden, genellikle yumuşak doku cerrahisinde kullanımı tercih edilmektedir. ${ }^{51}$ Er: YAG lazerler, dokudaki penetrasyon derinliğinin yüzeyel olması, ${ }^{52}$ su tarafından absorbe edilmesi ${ }^{51}$ ve ISI hasarı oluşturmaması ${ }^{51}$ gibi özelliklerinden dolayı diş sert dokularında kullanımı en uygun olan lazer tipi olarak gösterilmektedirler. ${ }^{53} \mathrm{Bu}$ bilgiler ışığında, araştırmamızda Er:YAG lazeri tercih ettik.

Lazer enerjisinin klinik uygulamalarda pulpal ve periodontal dokularda hasar oluşturmayacak enerji seviyesinde kullanılması önemlidir. Zach ve Cohen ${ }^{54}$ pulpada oluşan $5,6^{\circ} \mathrm{C}$ lik ISı artışının tolere edilebileceği ancak daha fazla ısı artışında pulpitis veya pulpa nekrozu oluşabileceğini bildirmektedir. Bu yüzden Er:YAG lazerin, çürük oluşumunu önlemede diş dokularında hasar oluşturmadan kimyasal değişikliklerin sağlandığı 
sub-ablativ enerji seviyesinde (100-250 mJ/atım) kullanımı önerilmektedir. ${ }^{47,53}$ Liu ve ark., ${ }^{19}$ minenin demineralizasyona karşı direncini arttırmada Er:YAG lazerin $100 \mathrm{mj}, 200 \mathrm{mj}$ ve $300 \mathrm{mj}$ enerji seviyesinde kullanımın etkisini değerlendirdikleri çalışmada, en iyi etkiyi $200 \mathrm{mj}$ uyguladıkları grupta gözlemlemişler ve koruyucu uygulamalar için Er:YAG lazerin 100-200 mj değerleri arasında kullanılması gerektiğini rapor etmişlerdir. Yapılan çalışmalarda, diş dokularının çürük oluşumuna karşı direncinin arttırılmasında sub-ablativ enerji seviyesinde kullanılan Er:YAG lazerin susuz kullanılmasının daha etkili olduğu ${ }^{28}$ su soğutması altında kullanıldığında ise istenen etkinin sağlanması için enerjisinin yüksek tutulması gerektiğinden çevre dokularda hasar oluşturduğu bildirilmektedir. ${ }^{19}$ Ayrıca lazerin atım aralığının da önemli olduğu ve atım aralığı uzadıkça lazerin oluşturduğu ısının arttığı ve enerjinin daha derin dokulara yayıldığı bildirilmektedir. ${ }^{55} \mathrm{Bu}$ sonuçlar göz önünde bulundurularak, araştırmamızda susuz olarak kullanılan Er:YAG lazer cihazı ile $200 \mathrm{mj}$ enerji seviyesinde ve $300 \mu$ s atım aralığında (kısa atım aralığı) çalıştık.

Çürük oluşumunu önlemede mine yüzeyine uygulanan lazer, kontakt ya da non-kontakt el aletiyle uygulanabilmektedir. Non-kontakt lazerler hedef dokulara dokunmadan etkileşim sağlamaktadır. Cecchini ve ark. ${ }^{26}$ minenin asit ataklarına karşı direncini arttırmada Er:YAG lazerin etkisini değerlendirdikleri çalışmalarında, kontakt ve $12 \mathrm{~mm}$ uzaklıktan non-kontakt uygulamanın benzer etki gösterdiğini, ancak kontakt uygulamanın diş yüzeyinde daha çok sayıda derin çatlak ve krater oluşumuna neden olduğunu ve bu sebepten dolayı çürük önleyici uygulamalarda nonkontakt lazer uygulamasının daha güvenli olduğunu ifade etmişlerdir. Bu bilgiler doğrultusunda, araştırmamızda lazer ışığı diş yüzeyine non-kontakt olarak 12 mm uzaktan uygulandı. Uygulama süresi boyunca 12 mm'ye ayarlı endodontik eğe el aletine sabitlendi ve bu şekilde uzaklık kontrolü sağlandı.

Yapılan birçok çalışmada, diş çürüğü oluşumunun engellenmesinde, asit atakları sırasında ortamda bulunan F'in, mine yüzeyindeki HAP kristallerinin çözünmesini engellediği ve minenin yapısına katılarak (FAP/FHAP) dayanıklıığını arttırdığı bildirilmektedir. ${ }^{6-8}$ Topikal $F$ uygulamaları ile FAP/FHAP oluşumundan daha ziyade, mine yüzeyinde $\mathrm{CaF}_{2}$ birikimi meydana gelmektedir. ${ }^{56}$ Günümüzde topikal $\mathrm{F}$ uygulamaların çürük oluşumunu engelleme gücü, $\mathrm{CaF}_{2}$ oluşturma kapasitesiyle açıklanmaktadır. Özellikle APF gibi düşük pH'ya sahip topikal $F$ ajanları kullanıldığında oluşan $\mathrm{CaF}_{2}$ miktarı daha fazla olmaktadır. ${ }^{57} \mathrm{CaF}_{2}$, asit atakları sırasında $\mathrm{F}$ salgılayan rezervuar gibi rol oynamakta ve yakın çevresinde artmış $F$ konsantrasyonunu devam ettirerek dişin remineralizasyonuna yardımc olmaktadır. ${ }^{56}$ Garcia-Godoy ve ark., ${ }^{58}$ minenin çürük oluşumuna karşı direncinin arttırımasında APF jelinin etkisini lezyon derinliği ölçümü yaparak değerlendirmişlerdir. Çalışma sonucunda, kontrol grubuna göre APF gruplarında daha düşük lezyon derinliği saptamışlar ve APF'nin çürük oluşumunu önlemede etkili olduğunu vurgulamışlardır. Çalışmamızda da, Garcia-Godoy ve ark.'nın ${ }^{58}$ çalışması ile uyumlu olarak, negatif kontrol grubu ile karşılaştırıldığında APF'nin çürük önlemede etkili olduğu tespit edildi. Bu bulgular SEM görüntülerinde $\mathrm{CaF}_{2}$ birikimlerinin gözlenmesi ile de desteklendi.

CPP-ACP, diş yüzeyine ve dental plağa bağlanarak kalsiyum ve fosfat deposu gibi rol oynamaktadır. ${ }^{59}$ Asit atakları sırasında CPP-ACP, kalsiyum ve fosfat iyonları salarak demineralizasyonu azaltıp remineralizasyonu desteklediği bildirilmektedir. ${ }^{36,60}$ Poggio ve ark. ${ }^{12}$ CPP-ACP patının mine demineralizasyonu üzerinde önleyici etkisi olduğunu belirtmişlerdir. Uysal ve ark., ${ }^{61}$ ortodontik braketler çevresinde mine demineralizasyonunu azaltmada $\mathrm{F}$ ve CPP-ACP içerikli topikal ajanların etkisini değerlendirdikleri çalışmalarında, her iki ajanında çürük oluşumunu başarılı bir şekilde inhibe ettiğini göstermişlerdir. CPP-ACP'nin mine yüzeyindeki etkisini SEM ile değerlendiren çalışmalarda ${ }^{43,62}$ ise, CPP-ACP'nin demineralizasyona karşı direnci arttırdığı, yüzeyde homojen bir remineralize tabaka oluşturduğu bildirilmektedir. Bu çalışmalara benzer şekilde, araştırmamızda negatif kontrol grubu ile karşılaştırıldığında, CPP-ACP'nin çürük oluşumuna karşı direnç sağladığı ve SEM görüntülerinde de mine yüzeyinin homojen bir remineralizasyon tabakası ile örtülü olduğu gözlendi.

Diş sert dokularının çürük oluşumuna karşı direncini arttırmada lazer uygulamalarının etkili olduğu bildirilmektedir. ${ }^{14,26,29}$ Lazer; minenin yüzey morfolojisinde (kristallerinin erimesi ve rekristalizasyonu), ${ }^{63}$ kimyasal kompozisyonunda değişimlere, ${ }^{21,63,64}$ ve kristalin faz transformasyonuna (daha az çözünen a-TCP ve $\beta$-TCP) ${ }^{14,21,64,65}$ neden olarak asit ataklarına karşı direncini arttırmaktadır. Lazer tedavisinden sonra organik matriks eriyerek porları bloke etmekte ve böylece iyon difüzyonunda azalmaya neden olarak demineralizasyon oluşumunu inhibe etmektedir. ${ }^{20,23}$ Ancak

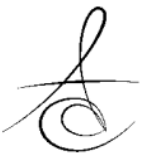


bazı araştırmacılar asit ataklarına karşı direncini arttırmada minenin yüzey topografisindeki değişimlerden daha çok kimyasal yapısındaki değişimlerin önemli olduğunu vurgulamaktadırlar. ${ }^{66}$ Lazer uygulaması sonucu minede ISı artışının meydana gelmesi, karbonat oranının azalmasına ve suyun uzaklaşmasına yol açarak organik kompozisyonunda kimyasal değişimlere neden olmaktadır. ${ }^{21,23,64}$ Böylece aside daha dirençli yeni bir kristal yapı (a-TCP ve $\beta$-TCP) oluşmaktadır. ${ }^{14,21,64}$ Cecchini ve ark. ${ }^{26}$ düşük enerji seviyesindeki Er:YAG lazerin mine yüzeyinde ciddi değişikler oluşturmadan minenin çözünürlüğünü azalttığını bildirmişlerdir. Hossain ve ark. ${ }^{28}$ spektrofotometre ve SEM analizi ile diş dokularının asit ataklarına karşı direncinin arttırılmasında Er:YAG lazerin etkisini değerlendirdikleri çalışmalarında lazerin etkili olduğunu belirtmişlerdir. Erbiyum lazerlerin minenin çürük oluşumuna karşı direncinin mikrosertlik ile değerlendirildiği in situ bir çalışmada da lazerin etkili olduğu gösterilmiştir. ${ }^{25}$ Liu ve ark. ${ }^{19}$ da PLM ile lezyon derinliği ölçümü yaparak, Er:YAG lazer uygulaması sonrası lezyon derinliğinde azalmalar gözlediklerini rapor etmişlerdir. Araştırmamızda da bu çalışmalarla uyumlu olarak, lazerin asit ataklar karşısında dişlerde çürük oluşumunu azalttığı tespit edildi. SEM incelemesi sonuçlarımızda da, lazerin mine yüzeyinde morfolojik değişiklikler oluşturarak minenin asit ataklar sırasında çözünürlüğünü azalttığını belirten araştırıcıların bulguları ${ }^{26,29,67}$ ile paralellik gözlenmektedir.

Çalışmamızda daimi dişlerde mine yüzey hazırlama işlemlerinden Er:YAG lazerin APF ve CPPACP ile karşılaştırılmasında, CPP-ACP ve Er:YAG grupları arasında istatistiksel olarak anlamlı bir fark gözlenmezken, diğer çalışmalarla uyumlu olarak, ${ }^{24,66}$ APF'nin lazerden daha etkili olduğu gözlendi. Araştırmamızda non-kontak ve düşük enerji seviyesinde uyguladığımız Er:YAG lazerin yeterli ısı artışı sağlamadığından karbonatın kısmi olarak uzaklaşmasına neden olduğunu ve bu yüzden de APF'ye göre minede daha az etki gösterdiğini düşünmekteyiz.

Çalışmamızda, Er:YAG lazer ve CPP-ACP'nin birlikte kullanımlarının lazerin tek başına kullanılmasına göre ilave bir katkı sağlamadığı saptandı. Dahası istatistiksel bir farklılık olmamasına rağmen, Er:YAG lazer ve CPP-ACP'nin birlikte uygulanmasının, CPPACP'nin tek başına uygulanmasına göre daha yüksek çürük lezyon derinlik değerine sahip olduğu gözlendi. Bunun, CPP-ACP'nin diş yüzeyindeki kalsiyuma ve fosfata bağlanarak etki göstermesi ${ }^{65}$ ve mineralize dokunun lazer uygulaması sonucu uzaklaştırımasına bağlı olarak CPP-ACP'nin bağlanacağı yüzeyin azalmasından kaynaklı olduğunu düşünmekteyiz. Ancak literatürde daimi diş minesinin çürük oluşumuna karşı direncinin arttırılmasında lazer ve CPP-ACP'nin birlikte kullanımı hakkında herhangi bir çalışmanın olmaması nedeni ile bu bulgumuz diğer araştırmalar ile karşılaştırılamadı.

Sonuç olarak, minenin çürük oluşumuna karşı direncinin arttırılmasında kullanılan APF, CPP-ACP ve Er:YAG lazer uygulamalarının daimi dişlerde çürük direncini arttırmada önlemede olumlu etkileri olmasına rağmen Er:YAG lazerin CPP-ACP ile birlikte kullanımın tek başına kullanıma göre ilave bir katkı sağlamadığı tespit edildi. Ancak bulgularımızı desteleyecek daha çok sayıda in vitro/vivo çalışmalar yapılmasına gereksinim olduğunu düşünmekteyiz.

Şule Bayrak, ORCID ID: 0000-0001-7023-2358

\section{KAYNAKLAR}

1. Zero DT. Dental Caries Process. Dent Clin North Am 1999;43:635-64.

2. Petersen PE. The World Oral Health Report 2003: Continuous Improvement of Oral Health in the 21st Century--the Approach of the WHO Global Oral Health Programme. Community Dent Oral Epidemiol 2003;31:3-23.

3. Selwitz RH, Ismail AI, Pitts NB. Dental Caries. Lancet 2007;369:51-9.

4. Uluçam S, Akal N, Fidan I, Cula S. Daimi Molar Dişlere Uygulanan Paslanmaz Çelik Kronların Dişeti Sağlığı Üzerine Etkisi. Gazi Üniv Diş Hek Fak Derg 2005;22:97-103.

5. Featherstone JD. Dental Caries: a Dynamic Disease Process. Aust Dent J 2008;53:286-91.

6. Featherstone JD. The Science and Practice of Caries Prevention. J Am Dent Assoc 2000;131:8879.

7. Featherstone JD, Glena R, Shariati M, Shields CP. Dependence of In Vitro Demineralization of Apatite and Remineralization of Dental Enamel on Fluoride Concentration. J Dent Res 1990;69:620-5.

8. ten Cate JM. In Vitro Studies on the Effects of Fluoride on De- and Remineralization. J Dent Res 1990;69:614-9. 
9. Featherstone JD. Prevention and Reversal of Dental Caries: Role of Low Level Fluoride. Community Dent Oral Epidemiol 1999;27:31-40.

10. Featherstone JD. Remineralization, the Natural Caries Repair Process: The Need for New Approaches. Adv Dent Res 2009;21:4-7.

11. Mascarenhas AK. Risk Factors for Dental Fluorosis: a Review of the Recent Literature. Pediatr Dent 2000;22:269-77.

12. Poggio C, Lombardini M, Dagna A, Chiesa M, Bianchi S. Protective Effect on Enamel Demineralization of a CPP-ACP Paste: an AFM In Vitro Study. J Dent 2009;37:949-54.

13. Yengopal V, Mickenautsch S. Caries Preventive Effect of Casein Phosphopeptide-Amorphous Calcium Phosphate (CPP-ACP): A Meta-analysis. Acta Odontol Scand 2009;67:321-32.

14. Featherstone JD. Caries Detection and Prevention with Laser Energy. Dent Clin North Am 2000;44:955-69.

15. Odabaş ME, Bodur H, Bariş E, Demir C. Clinical, Radiographic, and Histopathologic Evaluation of Nd: YAG Laser Pulpotomy on Human Primary Teeth. J Endod 2007;33:415-21.

16. Chimello DT, Serra MC, Rodrigues AL Jr, Pécora JD, Corona SA. Influence of Cavity Preparation with Er:YAG Laser on Enamel Adjacent to Restorations Submitted to Cariogenic Challenge In Situ: A Polarized Light Microscopic Analysis. Lasers Surg Med 2008;40:634-43.

17. Hossain M, Yamada Y, Masuda-Murakami Y, Nakamura $Y$. Removal of Organic Debris with Er:YAG Laser Irradiation and Microleakage of Fissure Sealants In Vitro. Lasers Med Sci 2012;27:895-902.

18. Tanboğa İ, Eren F, Altınok B, Peker S, Garip Berker Y, Özyöney G. Kök Kanal Tedavisinde ER:YAG Lazerin Smear Tabakası Üzerine Etkisi: SEM Çalışması. Atatürk Üniv Diş Hek Fak Derg 2011;21:74-81.

19. Liu JF, Liu Y, Stephen HC. Optimal Er:YAG Laser Energy for Preventing Enamel Demineralization. J Dent 2006;34:62-6.

20. Yamamoto H, Sato K. Prevention of Dental Caries by Acousto-optically Q-switched Nd:YAG Laser Irradiation. J Dent Res 1980;59:137.
21. Fowler BO, Kuroda S. Changes in Heated and in Laser-Irradiated Human Tooth Enamel and Their Probable Effects on Solubility. Calcif Tissue Int 1986;38:197-208.

22. Anderson JR, Ellis RW, Blankenau RJ, Beiraghi SM, Westerman GH. Caries Resistance in Enamel by Laser Irradiation and Topical Fluoride Treatment. J Clin Laser Med Surg 2000;18:33-6.

23. Hsu $C$, Jordan $T$, Dederich $D$, Wefel J. Effects of Low-energy $\mathrm{CO}_{2}$ Laser Irradiation and the Organic Matrix on Inhibition of Enamel Demineralization. J Dent Res 2000;79:1725-30.

24. Apel C, Meister J, Schmitt N, Gräber HG, Gutknecht N. Calcium Solubility of Dental Enamel Following Sub-ablative Er:YAG and Er:YSGG Laser Irradiation In Vitro. Lasers Surg Med 2002;30:337-41.

25. Apel C, Birker L, Meister J, Weiss C, Gutknecht N. The Caries-Preventive Potential of Subablative Er:YAG and Er:YSGG Laser Radiation in an Intraoral Model: A Pilot Study. Photomed Laser Surg 2004;22:312-7.

26. Cecchini RC, Zezell DM, de Oliveira E, de Freitas PM, Eduardo Cde P. Effect of Er:YAG Laser on Enamel Acid Resistance: Morphological and Atomic Spectrometry Analysis. Lasers Surg Med 2005;37:366-72.

27. Zezell DM, Boari HG, Ana PA, Eduardo Cde P, Powell GL. Nd:YAG Laser in Caries Prevention: A Clinical Trial. Lasers Surg Med 2009;41:31-5.

28. Hossain M, Nakamura $Y$, Kimura $Y$, Yamada $Y$, Ito M, Matsumoto K. Caries-preventive Effect of Er:YAG Laser Irradiation with or without Water Mist. J Clin Laser Med Surg 2000;18:61-5.

29. Apel C, Meister J, Götz H, Duschner H, Gutknecht N. Structural Changes in Human Dental Enamel After Subablative Erbium Laser Irradiation and Its Potential Use for Caries Prevention. Caries Res 2005;39:65-70.

30. Rodrigues LK, Nobre Dos Santos M, Featherstone JD. In Situ Mineral Loss Inhibition by $\mathrm{CO}_{2}$ Laser and Fluoride. J Dent Res 2006;85:617-21.

31. Tepper SA, Zehnder M, Pajarola GF, Schmidlin $P R$. Increased Fluoride Uptake and Acid Resistance by $\mathrm{CO}_{2}$ Laser Irradiation Through Topically Applied Fluoride on Human Enamel In Vitro. J Dent 2004;32:635-41. 
32. Sobral MA, Lachowski KM, de Rossi W, Braga SR, Ramalho KM. Effect of Nd:YAG Laser and Acidulated Phosphate Fluoride on Bovine and Human Enamel Submitted to Erosion/Abrasion or Erosion Only: An In Vitro Preliminary Study. Photomed Laser Surg 2009;27:709-13.

33. Moslemi M, Fekrazad R, Tadayon N, Ghorbani M, Torabzadeh $\mathrm{H}$, Shadkar MM. Effects of ER,Cr:YSGG Laser Irradiation and Fluoride Treatment on Acid Resistance of the Enamel. Pediatr Dent 2009;31:409-13.

34. ten Cate JM, Duijsters PP. Alternating Demineralization and Remineralization of Artificial Enamel Lesions. Caries Res 1982;16:201-10.

35. Longbottom C, Ekstrand K, Zero D. Traditional Preventive Treatment Options. Monogr Oral Sci 2009;21:149-55.

36. Reynolds EC, Cai F, Shen P, Walker GD. Retention in Plaque and Remineralization of Enamel Lesions by Various Forms of Calcium in a Mouthrinse or Sugar-Free Chewing Gum. J Dent Res 2003;82:206-11.

37. Karaman S, Durucan G. Pedodontide Koruyucu Tedaviler. Selçuk Üniv Diş Hek Fak Derg 1996;6:84-91.

38. Pai N, McIntyre J, Tadic N, Laparidis C. Comparative Uptake of Fluoride Ion into Enamel from Various Topical Fluorides In Vitro. Aust Dent J 2007;52:41-6.

39. Saxegaard E, Rölla G. Fluoride Acquisition on and in Human Enamel During Topical Application In Vitro. Scand J Dent Res 1988;96:523-35.

40. American Dental Association Council on Scientific Affairs. Professionally Applied Topical Fluoride: Evidence-Based Clinical Recommendations. J Am Dent Assoc 2006;137:1151-9.

41. Lennon AM, Pfeffer M, Buchalla W, Becker K, Lennon S, Attin T. Effect of a Casein/calcium Phosphate-containing Tooth Cream and Fluoride on Enamel Erosion In Vitro. Caries Res 2006;40:154-7.

42. Keçik D, Cehreli SB, Sar C, Unver B. Effect of Acidulated Phosphate Fluoride and Casein phosphopeptide-amorphous Calcium Phosphate Application on Shear Bond Strength of Orthodontic Brackets. Angle Orthod 2008;78:129-33.
43. Pai D, Bhat SS, Taranath A, Sargod S, Pai VM. Use of Laser Fluorescence and Scanning Electron Microscope to Evaluate Remineralization of Incipient Enamel Lesions Remineralized by Topical Application of Casein Phosphopeptide Amorphous Calcium Phosphate (CPP-ACP) Containing Cream. J Clin Pediatr Dent 2008;32:201-6.

44. Bayrak S, Tunc ES, Sonmez IS, Egilmez T, Ozmen B. Effects of Casein PhosphopeptideAmorphous Calcium Phosphate (CPP-ACP) Application on Enamel Microhardness After Bleaching. Am J Dent 2009;22:393-6.

45. Elsayad I, Sakr A, Badr Y. Combining Casein Phosphopeptide-Amorphous Calcium Phosphate with Fluoride: Synergistic Remineralization Potential of Artificially Demineralized Enamel or Not? J Biomed Opt 2009;14:044039.

46. Rehder Neto FC, Maeda FA, Turssi CP, Serra MC. Potential Agents to Control Enamel Caries-like Lesions. J Dent 2009;37:786-90.

47. Bevilácqua FM, Zezell DM, Magnani R, da Ana PA, Eduardo Cde P. Fluoride Uptake and Acid Resistance of Enamel Irradiated with Er:YAG Laser. Lasers Med Sci 2008;23:141-7.

48. Santaella MR, Braun A, Matson E, Frentzen M. Effect of Diode Laser and Fluoride Varnish on Initial Surface Demineralization of Primary Dentition Enamel: An In Vitro Study. Int J Paediatr Dent 2004;14:199-203.

49. Nelson DG, Jongebloed WL, Featherstone JD. Laser Irradiation of Human Dental Enamel and Dentine. N Z Dent J 1986;82:74-7.

50. Chiang YC, Lee BS, Wang YL, Cheng YA, Chen $\mathrm{YL}$, Shiau JS, Wang DM, Lin CP. Microstructural Changes of Enamel, Dentin-enamel Junction, and Dentin Induced by Irradiating Outer Enamel Surfaces with $\mathrm{CO}_{2}$ Laser. Lasers Med Sci 2008;23:41-8.

51. Coluzzi DJ. Fundamentals of Dental Lasers: Science and Instruments. Dent Clin North Am 2004;48:751-70.

52. Van As G. Erbium Lasers in Dentistry. Dent Clin North Am 2004;48:1017-159.

53. Apel C, Meister J, Ioana RS, Franzen R, Hering P, Gutkanecht N. The Ablation Threshold of Er:YAG and Er:YSGG Laser Radiation in Dental Enamel. Lasers Med Sci 2002;17:246-52. 
54. Zach L, Cohen G. Pulp Response to Externally Applied Heat. Oral Surg Oral Med Oral Pathol 1965;19:515-30.

55. Featherstone JD, Barrett-Vespone NA, Fried D, Kantorowitz Z, Seka W. $\mathrm{CO}_{2}$ Laser Inhibitor of Artificial Caries-like Lesion Progression in Dental Enamel. J Dent Res 1998;77:1397-403.

56. Ogaard B, Arends J, Schuthof J, Rølla G, Ekstrand J, Oliveby A. Action of Fluoride on Initiation of Early Enamel Caries In Vivo. A Microradiographical Investigation. Caries Res 1986;20:270-7.

57. Delbem AC, Cury JA. Effect of Application Time of $\mathrm{APF}$ and $\mathrm{NaF}$ Gels on Microhardness and Fluoride Uptake of In Vitro Enamel Caries. Am J Dent 2002;15:169-72.

58. Garcia-Godoy F, Hicks MJ, Flaitz CM, Berg JH. Acidulated Phosphate Fluoride Treatment and Formation of Caries-like Lesions in Enamel: Effect of Application Time. J Clin Pediatr Dent 1995;19:105-10.

59. Sudjalim TR, Woods MG, Manton DJ, Reynolds EC. Prevention of Demineralization Around Orthodontic Brackets In Vitro. Am J Orthod Dentofacial Orthop 2007;131:705.e1-9.

60. Sudjalim TR, Woods MG, Manton DJ. Prevention of White Spot Lesions in Orthodontic Practice: a Contemporary Review. Aust Dent J 2006;51:2849.

61. Uysal T, Amasyali M, Koyuturk AE, Ozcan S. Effects of Different Topical Agents on Enamel Demineralization Around Orthodontic Brackets: an In Vivo and In Vitro Study. Aust Dent J 2010;55:268-74.

62. Oshiro $M$, Yamaguchi $K$, Takamiza $T$, Inage $H$, Watanable T, Irokawa A, Ando S, Miyazakg M. Effect of CPP-ACP Paste on Tooth Mineralization: an FE-SEM Study. J Oral Sci 2007;49:115-20.

63. Ying D, Chuah G, Hsu C. Effect of Er:YAG Laser and Organic Matrix on Porosity Changes in Human Enamel. J Dent 2004;32:41-6.

64. Bachmann L, Craievich AF, Zezell DM. Crystalline Structure of Dental Enamel After Ho:YLF Laser Irradiation. Arch Oral Biol 2004;49:923-9.
65. Meurman JH, Hemmerlé J, Voegel JC, Rauhamaa-Mäkinen $R$, Luomanen $M$. Transformation of Hydroxyapatite to Fluorapatite by Irradiation with High-energy $\mathrm{CO}_{2}$ Laser. Caries Res 1997;31:397-400.

66. Delbem AC, Curry JA, Nakassima CK, Gouveia VG, Theodora LH. Effect of Er:YAG Laser on $\mathrm{CaF}_{2}$ formation and Its Anti-Cariogenic Action on Human Enamel: An In Vitro Study. J Clin Laser Med Surg 2003;21:197-201.

67. 67.Rodríguez-Vilchis LE, Contreras-Bulnes $R$, Sánchez-Flores I, Samano EC. Acid Resistance and Structural Changes of Human Dental Enamel Treated with Er:YAG Laser. Photomed Laser Surg 2010;28:207-11.

\section{Yazışma Adresi}

Prof.Dr.Şule Bayrak

Eskişehir Osmangazi Üniversitesi

Diş Hekimliği Fakültesi

Çocuk Diş Hekimliği Anabilim Dalı, Meşelik Kampüsü/ESKİŞEHİR

Tel: 0222 2393750/1485

Fax: 02222391273

e-mail: suleb76@yahoo.com 